\title{
Risk Analysis and Treatment on Seepage and Breaking of Tailings Dam
}

\author{
Guangming Yu, Yingnian Yu, Daning Wang, Irina V. Menshova, and Xiankun Zeng
}

\begin{abstract}
Online monitoring has been done in the Mengku tailings dam which stores iron ore. On September 14, 2016, the data of the monitoring points above $950 \mathrm{~m}$ were obviously abnormal, then the field investigation was immediately carried out. The investigation showed that there were serious seepage problems on the dam slope and the swamping phenomenon occurred on the surface of dam. On the basis of the project research and practice, analyzing the seepage problems with the hydraulic method that deduced by Darcy's law, calculating the seepage line equation of this segment and verifying the results by numerical simulation. The hydraulic gradient of spill point, the hydraulic gradient of flowing soil damage and the hydraulic gradient of piping damage are calculating, it found that the hydraulic gradient of spill point is less than the hydraulic gradient of flowing soil damage and the hydraulic gradient of piping damage, so a conclusion is drawn that the cross section has water seepage phenomenon, but the phenomenon doesn't lead to flowing soil damage or the piping damage. In order to quickly eliminate the accidents, some effective measures of precipitation should be used to avoid the happening of the dam damage.
\end{abstract}

Index Terms - Online monitoring, saturation line, Darcy's law, hydraulic gradient, piping damage, dam damage

\section{INTRODUCTION}

At 11:40 am on December 20, 2015, the landslides occurred in industrial region named Hengtaiyu in Phoenix community, Guangming New District, Shenzhen, Guangdong province, and the west to east gas pipeline exploded near here. There were 22 houses and factories were buried in the accident, the area of landslides were more than $1 \times 10^{5} \mathrm{~m}^{2}$. The main cause of the accident is that the wasted piles are too high, the time of storing cumulose soil is too long, there are not protective measures for supporting cumulose soil. So when the soil body falls from the high position, its potential energy is great and the accompanying damage is serious.

Tailings ponds are also the accumulation places storing

Manuscript received September 25, 2018, revised May 10, 2019. This work was supported by the National Natural Science Foundation of China (NSFC) under Grants 51674150.

Guangming $\mathrm{Yu}$ and Xiankun Zeng are with School of Civil Engineering, Cooperative Innovation Center of Engineering Construction and Safety in Shandong Blue Economic Zone, Qingdao University of Technology, Qingdao 266033, China (e-mail: yu-guangming@263.net, 2603696765@qq.com).

Yingnian $\mathrm{Yu}$ is with Qingdao Company, Zhongqi Jiaojian Group Co., Ltd., Qingdao 266300, China (e-mail: 1795556786@qq.com).

Daning Wang is with the Department of Informatics of Clausthal University of Technology, Clausthal-Zellerfeld 38678, Germany (e-mail: wangdaning_hans@hotmail.com).

Irina V. Menshova is with the Institute of Earthquake Prediction Theory and Mathematical Geophysics, Russian Academy of Sciences, Russia 117997, Russia (e-mail: menshovairina@yandex.ru). wasted cumulose soil and there is a lot of water in it, so the tailings ponds are major hazard sources [1]. According to the statistics data, the proportion of tailings dam accident due to seepage problems accounts for $30 \sim 40 \%$, so seepage safety has a very important problem in tailings ponds safety. With the height of tailings dams increasing, the dam seepage line also uplifts accordingly. At the same time, due to the deposit time of the different filling materials within the dam is different largely, and the change of the compactness, degree of consolidation and stress field of each part is larger, the permeability coefficient of each part of the tailings change largely as the change of dam stress and consolidation, which has great influence on dam seepage flow stability. Therefore, thorough understanding the seepage features in tailings dam, accurately determining the height of line seepage in the tailing dam and improving the stability of tailings dam is of great significance.

The regulation [2] stipulates that the online monitoring system must be installed on the first, second and third class tailings ponds. Mengku tailings dam belongs to the third class of tailings, and the author's research center in 2011 installed online monitoring system for this tailings dam, and made real-time monitoring of running status of it. On September 14, 2016, the data of saturation line monitoring point SYJ - 110 was apparently abnormal (Fig. 1 shows that the raw monitoring data of osmometer on the $950 \mathrm{~m}$ dam crest and near water penetration point), the field investigation was done and it showed that there were serious water seepage problems on the 940 950m dam slope and the swamping phenomenon occurred on the surface of dam, as shown in Fig. 2.

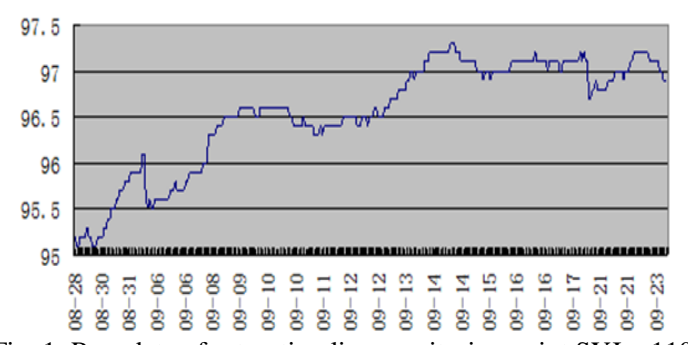

Fig. 1. Raw data of saturation line monitoring point SYJ -110 .

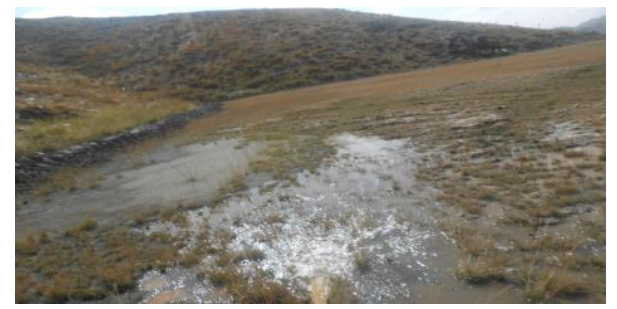

Fig. 2. Slope water seepage of Mengku dam.

As for the serious seepage problems of Mengku tailings dam, the research center immediately went to the field to 
check the dangerous situation, the relevant data was gotting. According to the field investigation situation analysis, the root cause of large-scale seepage is analyzed, the risk of dam break is judged, and the most reasonable control scheme is put forward.

\section{The REASON ANALysis OF ACCIDENT BASED ON THE HYDRAULIC METHOD}

On the research of seepage problem, the hydraulic method is a common and simple analysis method. And based on saturated Darcy's law, this method makes certain assumptions and simplified for seepage field, and gets hydraulic elements in [3], such as seepage line equation of seepage field, seepage flow of the dam and so on. The hydraulic elements of the seepage field gotten by hydraulic method are average seepage parameters, but the method is simple and it can satisfy the requirements of boundary conditions, so it is a very good method to calculate seepage field. As for the serious seepage problems on the 940 950m dam slope of Mengku tailings dam is analyzed by hydraulic method.

\section{A. Project Summary of Mengku Tailings Dam}

Mengku iron administrative region belongs to Fuyun County in Altay region, the Xinjiang Uygur Autonomous Region, and its geographic coordinates is east longitude

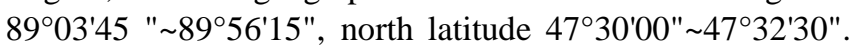
Mengku tailings dam belongs to upstream tailings dams, and the initial dam is rolled fill dam, and inner slope is laid waterproof geomembrane. The high of initial dam is $30 \mathrm{~m}$ which is built by earth-rock materials and wasted stone (soil: stone $=7: 3$ ). The materials are pressed layer-by-layer, and the thickness of materials in each layer are $300 \sim 600 \mathrm{~mm}$. After the design of heightening and dilatation, the late dam above more than $900 m$ is built by the upstream method, and eventually is piled up to $970 \mathrm{~m}$. The total dam is $90 \mathrm{~m}$ high with a total capacity of $2.0846 \times 10^{7} \mathrm{~m}^{3}$, and surface slope outside the initial dam is 0.4 , while the slope within the dam is 0.5 . The slope of surface on $900 \sim 940 m$ dam is 0.15 , the position of $940 m$ is a platform that is $116 m$, and the slope from $940 \sim$ $970 m$ adds to 0.2 . When seepage problem occurring, the measured dry beach is length of $15 \mathrm{~m}$.

\section{B. Saturated Darcy's Law}

French engineer Darcy used the permeability test of saturated sand layer to conclude to the Darcy's law that the seepage velocity and hydraulic gradient is proportional:

$$
v=k \frac{\Delta h}{L}=\frac{q}{A}=k i
$$

where $v$ is average flow velocity of the section, $k$ is the permeability coefficient of soil, $q$ is unit water percolating capacity, $i$ is the hydraulic gradient which shows the head loss of per unit length of seepage or called hydraulic grade.

\section{Basic Assumptions}

The seepage field in tailings ponds is very complicated. In the seepage calculation of tailings dam, it needs to be done to make the basic assumptions and simplifications to affecting factors and calculation conditions of penetration. There are many factors that can affect the permeability of tailings dam, such as the structure of tailing sand, porosity, saturation, the temperature of water, etc. These factors will affect the seepage field in tailings ponds. To be convenient for the study of engineering practical problems, some basic assumptions should be made for the dam above $940 \mathrm{~m}$ before calculation.

1) In the tailings dam, the seepage of fluid belongs to laminar flow, and is applicable to Darcy's law.

2) Ignoring the compressibility on soil when occurring seepage, and the soil porosity doesn't change.

3) The saturation of water in the soil remains unchanged.

4) The foundation of tailings dam is impervious.

In spite of there are lots of influence factors of seepage field in the tailings dam, but through a lot of engineering examples, as long as the basic assumptions and simplifies are within the permission scope, calculation results can satisfy the requirement of the engineering analysis precision.

\section{The Determination of Permeability Coefficient}

The permeability coefficient shows the strength of the soil infiltration capacity, and its size is associated with the types of soil, the gradation of soil particle, the compactness of soil, coefficient power and cohesive of seepage liquid and the temperature [4]. The determination of the permeability coefficient of soil can usually need to be used empirical method, laboratory test and field measurement method. The permeability coefficient of silt in Table I, $k=6 \times 10^{-3} \mathrm{~cm} / \mathrm{s}$, so the permeability coefficient of silt above $940 \mathrm{~m}$ is thought to be $k=6 \times 10^{-3} \mathrm{~cm} / \mathrm{s}$.

TABLE I: PERMEABILITy COEFFICIENT K OF ALL KINDS OF SOIL

\begin{tabular}{cccc} 
The kind of soil & $k(\mathrm{~cm} / \mathrm{s})$ & The kind of soil & $k(\mathrm{~cm} / \mathrm{s})$ \\
\hline Clay & $<6 \times 10^{-6}$ & Fine sand & $1 \times 10^{-3} \sim 6 \times 10^{-3}$ \\
Clay loam & $6 \times 10^{-6} \sim 1 \times 10^{-4}$ & Medium sand & $6 \times 10^{-3} \sim 2 \times 10^{-2}$ \\
Light clay loam & $1 \times 10^{-4} \sim 6 \times 10^{-4}$ & Coarse sand & $2 \times 10^{-2} \sim 6 \times 10^{-2}$ \\
The loess & $3 \times 10^{-4} \sim 6 \times 10^{-4}$ & Round gravel & $6 \times 10^{-2} \sim 1 \times 10^{-1}$ \\
Silt & $6 \times 10^{-4} \sim 1 \times 10^{-3}$ & The pebble & $1 \times 10^{-1} \sim 6 \times 10^{-1}$ \\
\hline
\end{tabular}

\section{E. The Establishment of the Cross Section Calculation Diagram}

According to the plan of Mengku tailings dam, the diagram of the whole seepage section is showed in Fig. 3 after generalization. The seepage section above $940 \mathrm{~m}$ in the Mengku tailings dam, the $X$ axis is the intersection line of the $940 m$ plane and principal plane the $Y$ axis is the line that representing the dry beach which is $15 \mathrm{~m}$ long. And then plane rectangular coordinate system is established. The calculation diagram of the seepage section is shown in Fig. 4. In the picture, $C$ represents the spill point, $\mathrm{H}_{1}=30 \mathrm{~m}, L_{2}=165 \mathrm{~m}$, the slope of the section is $1: 5$.

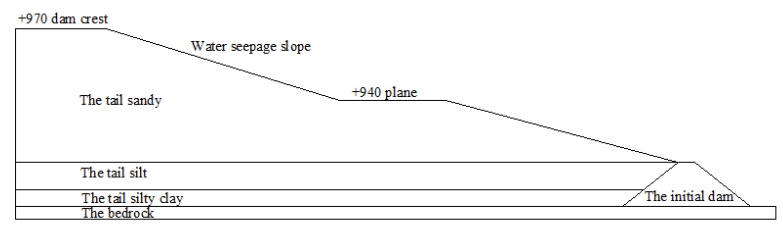

Fig. 3. Diagram of the whole seepage section. 


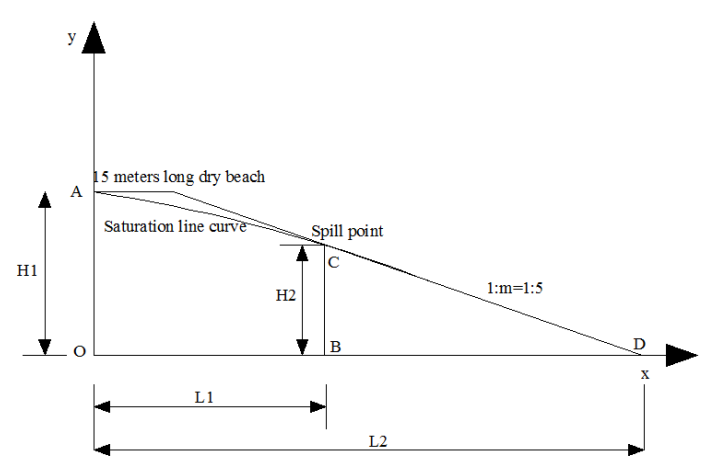

Fig. 4. Calculation diagram of the seepage section.

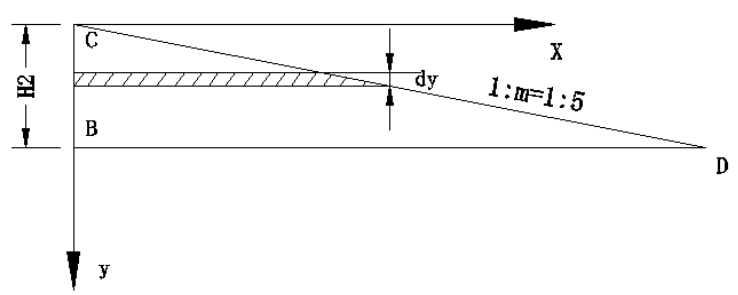

Fig. 5. Calculation diagram of the downstream dam.

\section{F. The Calculation of Saturation Line Equation}

1) The analysis of the upstream section

In the problem analysis of two-dimensional seepage, the thickness is 1 . So according to Darcy's law, the curve equation of seepage line is

$$
q=k A i=k y i=k y \frac{d_{y}}{d_{x}}
$$

where $q$ is the seepage flow of unit thickness, $\mathrm{m}^{2} / \mathrm{s} . K$ is the permeability coefficient, $\mathrm{m} / \mathrm{s}$. $A$ is the cross-sectional area, $\mathrm{m}^{2}$. $I$ is the hydraulic grade.

Computing the integral $x$ in equation (2), the integral interval is $(0, x)$,

$$
q x=\frac{1}{2} k y^{2}+M
$$

According to the plan, the seepage line crosses the point $A$ $(0,30)$. Substituting point A to equation (3) and calculating constant $M, M=-450 \mathrm{k}$, and substituting $C$ into equation (3) getting the equation as follows.

$$
y^{2}=900-\frac{2 q}{k} x
$$

Substituting the spill point $C\left(L_{1}, H_{2}\right)$ into equation (4),

$$
q=k \frac{900-H_{2}^{2}}{2 L_{1}}
$$

According to the geometric figure of the dam surface, $L_{l}=165-5 H_{2}$, so the equation (5) can be written as

$$
q=k \frac{900-H_{2}^{2}}{330-10 H_{2}}
$$

\section{2) The analysis of the downstream section}

In the new rectangular coordinate system, the spill point $C$ is the center of the circle. The $x$ axis is the line towards the right and the $y$ axis is the line towards the down, and then system of rectangular coordinates is established, the calculation diagram of the downstream dam as shown in Fig. 5.

The integral $q$ is working out, the integrating range is $(0$, $\mathrm{H}_{2}$ ), the seepage flow $q$ of downstream section is

$$
q=\int_{0}^{H_{2}} d q=\int_{0}^{H_{2}} k i d y=\frac{k}{m} \int_{0}^{H_{2}} d y=\frac{k H_{2}}{5}
$$

According to equation (6) and (7), the unknown quantities are

$H_{2}=19.25 \mathrm{~m}, q=2.31 \times 10-4 \mathrm{~m}^{2} / \mathrm{s}$.

Substituting $q$ into equation (4), the equation of saturation line is

$$
y^{2}=900-7.7 x
$$

Through the calculation above, the conclusion is shown as follow.

The equation of saturation line is $y^{2}=900-7.7 x$

The seepage flow, $q=2.31 \times 10-4 \mathrm{~m}^{2} / \mathrm{s}$.

The coordinates of spill point $C$ is $(68.75,19.25)$, which shows that water will overflow on the dam slope that is $19.25 \mathrm{~m}$ higher than $940 \mathrm{~m}$ plane that is very consistent with actual situation.

\begin{tabular}{|c|c|c|c|c|c|c|c|}
\hline $\begin{array}{l}\text { Name of } \\
\text { materials }\end{array}$ & $\begin{array}{l}\text { Modulus of } \\
\text { elasticity } \\
(\mathrm{N} / \mathrm{m})\end{array}$ & $\begin{array}{l}\text { Density } \\
\left(\mathrm{kg} / \mathrm{m}^{3}\right)\end{array}$ & $\begin{array}{c}\text { Natural bulk } \\
\text { density } \\
\left(\mathrm{kN} / \mathrm{m}^{3}\right)\end{array}$ & $\begin{array}{c}\text { Floating } \\
\text { density } \\
\left(\mathrm{kN} / \mathrm{m}^{3}\right)\end{array}$ & Cohesion $(\mathrm{kPa})$ & $\begin{array}{l}\text { Angl } \\
\text { e of } \\
\text { inter } \\
\text { nal } \\
\text { fricti } \\
\text { on } \\
\left({ }^{\circ}\right)\end{array}$ & $\begin{array}{l}\text { The permeability coefficient } \\
\qquad(\mathrm{cm} / \mathrm{s})\end{array}$ \\
\hline Tailing Sand & 57 & 1870 & 18.7 & 8.5 & 15.5 & 29.4 & $6.00 \mathrm{E}-3$ \\
\hline Tailing silt & 59 & 1900 & 19.0 & 9.0 & 22.4 & 23.7 & $6.00 \mathrm{E}-4$ \\
\hline Clay & 61 & 1820 & 18.2 & 8.5 & 14.4 & 25.4 & $3.89 \mathrm{E}-5$ \\
\hline $\begin{array}{l}\text { The materials } \\
\text { of initial dam }\end{array}$ & 7000 & 2190 & 18.0 & 8.0 & 8.0 & 40.0 & $3.10 \mathrm{E}-3$ \\
\hline
\end{tabular}

\section{NumERICAL SIMULATIONS TO CHECK CALCULATION}

\section{A. The Selection of Numerical Calculation Parameter}

The physical and mechanical properties of dam body materials which belong to Mengku tailings dam as shown in Table II.

TABLE II: PysicAl AND MEChANICAL PROPERTIES OF DAM Boby MATERIALS 


\section{B. Seepage Model and Boundary Conditions}

The section mesh is divided into quadrilateral elements by the software MIDAS/GTS as shown in Fig. 6. After meshing, there are 4256 nodes and 1449 elements in the model.

Seepage boundary condition is regarding initial dam, fill dam crest and dry beach as permeable dam slope, and regarding the junction of tail silt clay and bedrock as impervious boundary, the water level in tailings dam is $90 \mathrm{~m}$ high.

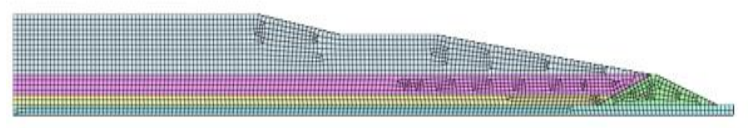

Fig. 6. Seepage model grid of Tailings dam.

\section{The Results of Numerical Simulation}

The whole section of seepage was simulated by the software MIDAS/GTS, according to the steady seepage mathematical model and its calculation principle, the seepage of tailings dam body is analyzed, and the pore water pressure nephogram is obtained. In Fig. 7, the position of the red line is the position of pore water pressure 0 , which can be regarded as the position of the saturation line of the section. It can be seen in the figure that there are spillover points at about 15 meters above $940 \mathrm{~m}$, i.e. seepage phenomena from spillover point to $940 m$ dam surface, which is in accordance with the actual situation and the results of hydraulic calculation.

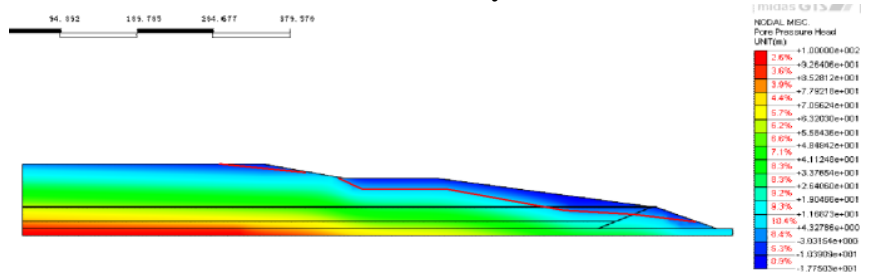

Fig. 7. Hydraulic head cloud picture of pore pressure.

\section{ANAlysis OF SEEPAGE DAMAgE}

From the theoretical calculation and the results of numerical simulation, seepage problems will appear on the 940 960m dam surface. Swamping is very serious at the same place in the actual situation, which seriously affects the normal operation of the tailings dam. But this does not mean that seepage damage must cause dam break. Usually seepage includes normal seepage and abnormal seepage. Normal seepage is advantageous to the tailings drainage and consolidation of dry beach, and it can improve the overall stability of the dam. Abnormal seepage is very bad, even may cause dam break. If the seepage part has problems that the involving soil is poor or the dam slope is too steep, it is easy to lead to flow or piping damage, seriously can lead to the dam break. So once appearing the abnormal seepage phenomenon, problems must be handled carefully.

\section{A. Analysis of Flow Soil Damage}

Flowing soil damage is a common form of tailings dam seepage failure. Flowing soil is the phenomenon of a range of soil mass or particle in the surface layer suspend and move at the same time under the influence of the seepage flow upward
[4]. Flowing soil can occur in the cohesive soil and coarse grained soil, and the critical hydraulic gradient of flow soil damage generally is:

$$
i_{c r}=\gamma^{\prime} / \gamma_{w}
$$

where $\gamma^{\prime}$ is the submerged unit weight of soil, $k N / \mathrm{m}^{3}, \gamma_{w}$ is the severe of water, $\mathrm{kN} / \mathrm{m}^{3}$.

The soil above $940 \mathrm{~m}$ plane is tailings silt. According to the survey report of Mengku tailings dam, the floating severe of tailings sand is $8.5 \mathrm{kN} / \mathrm{m}^{3}$, the severe of water is $10 \mathrm{kN} / \mathrm{m}^{3}$. By the formula (9), it concludes that the critical hydraulic gradient of flow soil damage is $i_{c r}=8.5 / 10=0.85$.

\section{B. Analysis of Piping Damage}

Piping is the phenomenon that fine particles in soil move and go away in the pore channels that coarse particles form under the action of seepage flow [6], [7]. The phenomenon of piping were mostly happened in sand soil with the characteristics that difference of particle size is larger and often lack of a certain particle size. Many scholars have proved the piping damage will happen in the tailing sand [8 10]. Piping was happened along the flow direction. When the piping occurs, fine particles were taken firstly, and the channel is formed between the coarse particles. Once the skeleton that is formed between the coarse particles cannot continue to support, the piping damage happens. Generally speaking, the critical hydraulic gradient of piping failure is considered to be the Kantrachev formula [11].

$$
i_{c r}=\frac{\left(\frac{\gamma_{s}}{\gamma_{w}}-1\right)}{\left[1+0.43\left(\frac{d}{d_{0}}\right)^{2}\right]}
$$

where $\gamma^{\prime}$ is the severe of soil grain, $k N / m^{3}, \gamma_{w}$ is the severe of water, $k N / \mathrm{m}^{3}, D$ is the size of lost particle, $m m, d_{0}$ is the hydraulic equivalent diameter, $d_{0}=0.214 n d_{50}, m m, d_{50}$ is the middle size of soil particle, $m m, n$ is the porosity.

According to the survey report of Mengku tailings dam, the floating severe of tailing sand is $8.5 \mathrm{kN} / \mathrm{m}^{3}$, the severe of water is $10 \mathrm{kN} / \mathrm{m}^{3}$, the size of lost particle is $d=0.005 \mathrm{~mm}$, the middle size of soil particle is $d_{50}=0.120 \mathrm{~mm}$, the porosity is $n=45 \%$. By the formula (10), the critical hydraulic gradient of piping damage is $i_{c r}=0.67$.

The hydraulic gradient $i$ where spilling the water from the dam can be calculated according to the formula below:

$$
i=\frac{1}{\sqrt{1+m^{2}}}
$$

where $m$ is the slope coefficient. Calculating to $i=0.20$. The hydraulic gradient of spill point calculated is less than the hydraulic gradient of flowing soil damage and the hydraulic gradient of piping damage, so the conclusion that the cross section has water seepage phenomenon, but it doesn't lead to 
flowing soil damage or the piping damage. Although the seepage damage of dam surface can't happen, but the phenomenon of water seepage is very serious, which affects the normal management and use of tailings dam.

\section{Length Calculation of SAFE Dry Beach}

Too short dry beach may lead to the phenomenon that seepage line increases sharply, and too high seepage line may lead to the problem of water seepage, even the seepage damage occurs. So the too short dry beach is the root cause of seepage damage. Three levels of tailings dam requires the depth of seepage line is at least $6 \mathrm{~m}$ deep. So the calculation of safe dry beach length is the key to solve the problem of the seepage on the dam surface.

It assumed the length of dry beach that needed to be increased is $l \mathrm{~m}$. At this time, moving the $y$ axis to the left $l \mathrm{~m}$ in rectangular coordinate system in Fig. 4. The new rectangular coordinate system established is shown in Fig. 8.

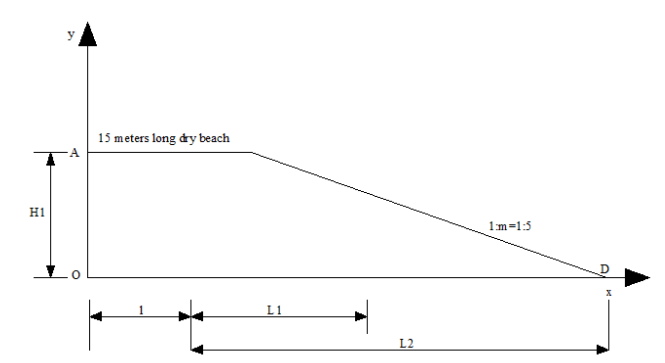

Fig. 8. New seepage plan in the Cartesian coordinate system The equation of the seepage line becomes.

$$
y_{1}^{2}=900-7.7(x+l)
$$

The linear equation of dam surface is

$$
y_{2}=-0.2 x+33
$$

The depth of seepage line $\Delta h$ is

$$
\Delta h=y_{2}-y_{1}=-0.2 x+33-\sqrt{900-7.7(x+l)}
$$

$\Delta h$ is derived function of $x$

$$
\Delta h^{\prime}=y_{2}^{\prime}-y_{1}^{\prime}=-0.2+\frac{7.7}{2 \sqrt{900-7.7(x+l)}}
$$

If $\Delta h^{\prime}=0$, then $x=68.75-l$. If $\Delta h^{\prime}<0$, then $x<68.75-l$. If $\Delta h^{\prime}>0$, then $x>68.75-l$. So the minimum value of $\Delta h$ will occur if $x=68.75-l$.

Assuming $\Delta h=6, x=68.75-l$, according to the formula (12), $l=30 m$, so the depth of equation line is $6 m$ deep at least, and the dry beach length of this cross section is $15+30=45 \mathrm{~m}$.

The regulation [12] stipulates that as for third class upstream tailings ponds, the minimum length of dry beach is $70 \mathrm{~m}$. So the too short dry beach is the root cause of the seepage damage. It should be done that strengthening the work of dry beach length control in the production operation, once there are abnormal conditions appearing, effective measures are should be taken immediately to ensure the stability of the dam.

\section{RISK TREATMENT}

Although the seepage damage of dam surface will not happen, but the phenomenon of seepage problems is very serious, which affect the normal management and use of tailings dam. So the development of abnormal seepage must be taken to control. At the beginning of swamping on the dam surface, mine party has taken the method of embedding precipitation pipe on the dam surface, but the effect is not ideal. To quickly eliminate the accidents, according to the condition of site, a more effective way of precipitation is adopt firstly.

Because the permeability coefficient of tailing sand is low, the light well point precipitation method are adopted to decrease the underground water level, which are feasible and the result is good both in theory and in practice. The principle of light well point precipitation is that forming vacuum area in the pipe with vacuum pump under the suction action of the vacuum pump, after filtering through pipe groundwater near the well point, is forced to breathe well point pipe and discharged through the pipe, so as to lower underground water level. In order to quickly reduce the saturation line, the light well point precipitation system is installed on the $950 \mathrm{~m}$ dam trail. Precipitation well is a total of 100, and two of the vacuum jet pump, the site layout is shown in Fig. 9.

Fig. 9 the light well point precipitation in the scene of construction

At the beginning of building $970 \mathrm{~m}$ dam, due to too small length of dry beach, the height of seepage line in $950 \mathrm{~m}$ downstream dam increased quickly. After using the light well point precipitation method, the further increased trend of the seepage line become under control. Lately as the work of building dam completed, dry beach length increases gradually and the seepage line gradually stable in a safe state. After emergency treatment for the accident, it is recommended that the ore party adjust the reasonable way of damming, so as to avoid the length of dry beach appearing too small during dam.

\section{CONCLUSIONS}

The seepage problems on the 940 960m's dam surface in Mengku tailings dam are mainly analyzing, it's summarized the following conclusions.

1) The cross section has the seepage phenomenon, but is can't lead to flowing soil damage or the piping damage.

2) Too short dry beach is the root cause of seepage damage.

3) The light well point precipitation method can quickly and effectively solve the problem of seepage problem on the tailings dam surface.

4) The conclusions of the above analysis and practice can provide theoretical basis and reference for solving similar problems of tailings dam permeability.

\section{ACKNOWLEDGMENT}

Thanks to the National Natural Science Foundation of 
China (51674150), supported by the Cooperative Innovation Center of Engineering Construction and Safety in Shandong Blue Economic Zone, Qingdao University of Technology. At the same time, we thanks to Yanhua Zuo and Ju Qiu of Qingdao University of Technology, Mikhail D.Kovalenko and Alexander P.Kerzhaev of Institute of Earthquake Prediction Theory and Mathematical Geophysics of Russian Academy of Sciences, Weiquan Wang of Fuyunmengku Iron Ore Co. Ltd. and Xin Dong of China Shandong Zhaojin Company for the works done for this article.

\section{REFERENCES}

[1] China Non-ferrous Metals Industry Association, "GB 50547-2010 Technical specification of tailings fill dam in geotechnical engineering (National standard of the People's Republic of China)," China Planning Press, Beijing, 2010.

[2] State Administration of Work Safety of the People's Republic of China, "AQ 2030-2010 Technical specification for dam safety monitoring (Industry standard of safety production of the People's Republic of China)," China Coal Industry Publishing House, Beijing, 2010.

[3] S. F. Li, "The study of stability and seepage belong to phosphogypsum yard dam," Kunming University of Science and Technology, Master's thesis, 2011.

[4] D. S. Sun, P. Liu, X. H. Xia, and J. H. Wang. "Permeability coefficient of unsaturated soils," Journal of Hydraulic Engineering, vol. 3, pp. $71-75,2004$

[5] G. X. Li and X. J Zhou. "Seepage damage of soil and its engineering problems," Engineering Survey, vol. 5, pp. 10-13+52, 2004

[6] R. Whitlow, "Basic soil mechanics (3rd edition)," Longman Malaysia, 1995.

[7] Z. Y. Chen, J. X. Zhou, and H. J. Wang, Soil Mechanics, Tsinghua University Press, Beijing, 1992.

[8] Y. Wei, A. W. Zhao, and K. L. Xu, "The test of tailings dam piping damage," Metal Mine, vol. 9, pp. 157-160, 2015.

[9] X. Zheng, Y. Kang, K. 1. Xu, and X. H. Xu. "Experimental study of tailings dam piping," Industrial Safety and Environmental Protection, vol. 6, pp. 37-39, 2003.

[10] X. Ni and L. and X. Lv, "The identification method and application of tailings dam piping damage," Protection and Utilization of Minerals. vol. 2, pp. 50-53, 2013.

[11] K. J. Bathe, "Finite element proceduresin engineering analysis," Prenfce-Hall, Inc, 1982.

[12] State Administration of Work Safety of the People's Republic of China, "AQ2006-2005 Safety and technical regulations of tailings dam (Industry standard of safety production of the People's Republic of China)," China Coal Industry Publishing House, Beijing, 2006.

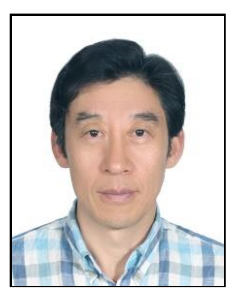

Guangming $\mathbf{Y u}$ received the bachelor degree in mine surveying from Liaoning Technical University, Fuxin, China in 1986, the master degree in mine surveying from Liaoning Technical University, Fuxin, China in 1988 , the doctor degree in engineering mechanics from China University of Mining and Technology in 1997, and postdoctoral research at Silesica University of Technology, Poland in 1998, respectively.

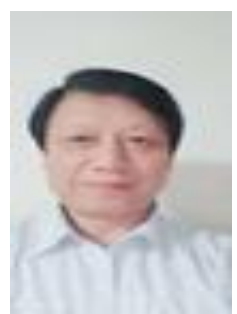

Yingnian $\mathbf{Y u}$ received the bachelor degree in construction engineering from the People's Liberation Army University of Science and Technology in 2001. $\mathrm{He}$ engaged in three coal mining ground building protection work in Jixi Mining Bureau from 1983 to 1993. Since 1993, he has worked as a construction technician and project manager in Zhongqi Construction Group Co., Ltd., engaged in project construction and project management.
He worked as associate professor, professor, supervisor of master and doctor in Liaoning Technical University, Fuxin, China from 1997 to 2000 He has been a professor of School of Civil Engineering at Qingdao University of Technology, Qingdao, China from 2001, he is also a national candidate of the New Century Talents Project in China, the specialist who enjoys special subsidies from the State Council of the people's Republic of China and the director of Engineering Technique Research Center of Rock Mass Damage and Ground Subsidence Control and Treatment, Shandong Province. He has won 6 national, provincial and ministerial awards, such as the 2 nd prize of national science and technology progress.

Prof. Yu presided over 65 items of the National Natural Science Foundation, Sino-Russian International Cooperation and subway construction projects. His primary research interests in underground engineering construction, building health maintenance and disaster monitoring of civil engineering.

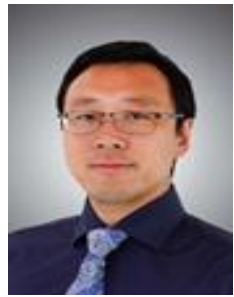

Daning Wang received the master degree from Department of Informatics of Clausthal University of Technology, Germany in 2009, the doctor degree from Department of Informatics of Clausthal University of Technology, Germany in 2016, respectively.

$\mathrm{He}$ is currently an assistant researcher and master's supervisor of Department of Informatics of Clausthal University of Technology, Germany. His mainly research interests in soft engineering.

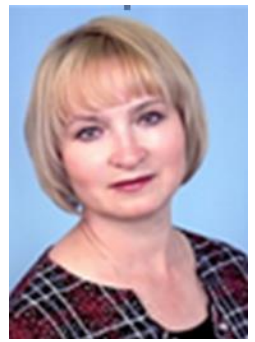

Irina V. Menshova received the bachelor degree from department of mathematics of Irkutsk State University, Russia in 1986, the master degree from department of mathematics of Irkutsk State University, Russia in 1989, the doctor degree from department of applied mathematics of Moscow State Open University named after V.S Chernomyrdin, Russia in 2010, respectively.

She worked as an associate professor in Moscow State Technical University from 2011 to 2014. She has been a senior researcher in Institute of Earthquake Prediction Theory and Mathematica Geophysics of Russian Academy of Sciences from 2015. Senior researcher Irina V.Menshova's primary research fields in the biharmonic problem and boundary value problems of the theory of elasticity.

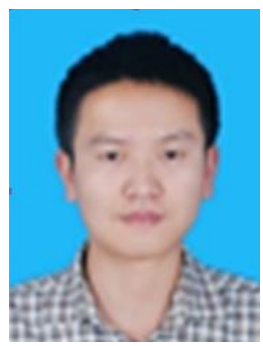

Xiankun Zeng is now a $\mathrm{PhD}$ student in the School of Civil Engineering of Qingdao University of Technology in China. In 2018, he received the master degree in civil engineering from the College of Architecture and Civil Engineering of Xinjiang University in China. In 2015, he received the bachelor degree in civil engineering from the College of Post and Telecommunication of Wuhan Institute of Technology in China.

His currently research interests in geotechnical engineering, including deformation monitoring of tailing dam and the influence analysis of subway tunnel or foundation pit construction on surrounding environment 